\title{
Creative social media use for Covid-19 prevention in Bangladesh: a structural equation modeling approach
}

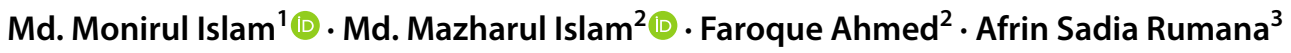

Received: 31 December 2020 / Revised: 17 March 2021 / Accepted: 18 March 2021 / Published online: 10 April 2021

(c) The Author(s), under exclusive licence to Springer-Verlag GmbH Austria, part of Springer Nature 2021

\begin{abstract}
In recent years, information dissemination has been quicker than earlier years with the sky-high development of diverse social media platforms, e.g., Facebook, WhatsApp, Twitter, YouTube and so on, which are more used in creative production. This advancement of social media disclosures has numerous merits and demerits to prevent and control contagious diseases like the Covid-19 pandemic. In this respect, this research scrutinizes the role of creative social media use in preventing the Covid-19 outbreak in Bangladesh utilizing the structural equation modeling (SEM) approach. To this end, this study uses an online survey from June to October 2020 engaging $265(N=265)$ Bangladeshi people as respondents at different ages. The study results establish that creative social media use helps enhance the knowledge of Covid-19 precautions online, and this pertinent knowledge contributes to preventing Covid-19 outbreak in Bangladesh. It implies that creative social media use has a significant indirect effect on Covid-19 prevention, whereas knowledge of Covid-19 precautions online mediates this relationship between creative social media use and Covid-19 prevention. The results also discover that the educational level of the people has a significant direct and positive impact on Covid-19 prevention. Therefore, the study suggests more creative use of social media in preventing the spread of the Covid-19 epidemic in Bangladesh.
\end{abstract}

Keywords Creative social media use $\cdot$ Knowledge of Covid-19 precautions online $\cdot$ Covid-19 prevention $\cdot$ SEM approach $\cdot$ Bangladesh

Md. Mazharul Islam

mislam6@isrt.ac.bd

Md. Monirul Islam

monirdu1981@gmail.com; monirul.islam@bigm.edu.bd

Faroque Ahmed

faroque.ahmed@bigm.edu.bd

Afrin Sadia Rumana

arumana@isrt.ac.bd

1 Department of Governance and Public Policy, Bangladesh Institute of Governance and Management (BIGM), University of Dhaka (Affiliated), Dhaka, Bangladesh

2 Bangladesh Institute of Governance and Management (BIGM), University of Dhaka (Affiliated), Dhaka, Bangladesh

3 Faculty of Business Studies, Bangladesh University of Professionals (BUP), Dhaka, Bangladesh

\section{Introduction}

The spread of Covid-19 infection has been growing rapidly among 218 countries and territories with more than $77,220,594$ confirmed infection cases and more than $1,700,591$ deaths as of 21st December 2020 (Worldometer 2020). This severity of Covid-19 outbreak rates highly supports the World Health Organization (WHO)'s statement of "pandemic" that is snatching the lives of world people every day (Lin et al. 2020). Beyond the diagnosed symptoms of Covid-19 such as fever, dry cough, weakness, dyspnea and myalgia, people might be affected by similar types of influenza (Wang et al. 2020a, b; Wong, Leo and Tan 2020). Due to the lack of symptom determination of Covid-19, the infection control has been quite difficult and the doctors' services, in this case, are not always well-enough to help people for the detection and treatment of Covid-19. This situation makes people to highly be dependent on media (electronic and printing) and the internet especially social media to detect and prevent the Covid-19 disease amidst the faster rate of infections. 
Social media has become a source of disseminating information to the public during the Covid-19 pandemic (Ahmad and Murad 2020). Many individuals have experienced isolation in hospitals or while quarantining at home. In this situation, social media has been the only source of information. Social media is an effective resource of information and an efficient way of gathering necessary knowledge for medication and treatment (Holmbom 2015). As social media is used for people-oriented as well as creative activities through providing information, this state of social media use is termed as creative social media use. People's gratification is correlated with the creative use of social media (Whiting and Williams 2013). For example, most people choose this type of social media platform and look for information on this media instead of using the different official webpage of health authority because of convenient use and availability of multifarious instructive data relating to diseases. Thus, the rate of creative social media use has been increased dramatically among people living in different parts of the world.

Bangladesh as a developing country with its inhabitants of 165 million (Islam and Islam 2021) has witnessed a total of 509,148 Covid-19 confirmed cases where 451,961 $(88.8 \%)$ patients recovered, 7,452 (1.46\%) died and 49,735 (9.77\%) were found as active cases as of 27 th December 2020 (WHO 2021). The first Covid-19 case in Bangladesh was detected on March 8, 2020 (Worldometer 2020). Then, the government of the country imposed maintaining social distance, isolation and home quarantine to reduce the infection rates (Islam, Sujan et al. 2020). Besides, a countrywide lockdown was declared by the Bangladesh government on May 25, 2020, because of discovering 367 infected cases within a short two months Islam (2020).

During the lockdown, the people of Bangladesh highly relied on internet-based social media to know the infectionrelated information, preventive measures and treatment of the Covid-19 pandemic as the healthcare facilities were not up-to-the-mark regarding the infection rates and death tolls. The healthcare system of the country experiences a lack of dependability, receptivity and sympathy, which is proved with its inadequate Medicare service delivery to the public (Mohiuddin 2019). Besides, medical facilities are usually urban area-centric and rural poor people are deprived of proper treatment with developed medical equipment, good doctors and well-equipped hospitals (Sampa et al. 2020). Doctors' panic to treat the Covid-19 patients has been a crucial issue in the healthcare system in Bangladesh. In some cases, some doctors were dismissed from their service due to showing reluctance to serve the patients (Swazo et al. 2020). Overall, the loopholes of the healthcare system of Bangladesh are characterized using three points: "poor governance and increased corruption, inadequate healthcare facilities and weak public health communication" (Al-Zaman 2020).
This situation of the healthcare system in Bangladesh compelled the people using the internet as well as social media to face the Covid-19 outbreak. More growth of the internet and social media uses of Bangladeshi citizens helped inform each other of dealing with the Covid-19 pandemic. In Bangladesh, total internet users account for 66.44 million (40.27\% of the total population) in January 2020, whereas 36.00 million ( $21.82 \%$ of the total population) people were social media users. The quantity of social media users rose by 3.0 million (+9.1\%) from April 2019 to January 2020, and the people's accessed rate of social media arrived at $22 \%$ in January 2020 (Simon 2020). The latest report disclosed by the GlobalStat (2021) reveals that social media users in Bangladesh include Facebook (85.85\%), YouTube (3.88\%), Twitter (8.81\%), WhatsApp (0.82\%), LinkedIn (0.46\%), Instagram $(0.08 \%)$, Reddit $(0.06 \%)$ and Tumblr $(0.04 \%)$ as of December 2020. This escalating use of social media thus plays a significant creative role in dealing with the Covid-19 outbreak in Bangladesh while people were staying in-home quarantine, witnessing countrywide lockdown and admitted to hospitals in the first wave of the epidemic. This scenario requires investigating the role of social media in preventing Covid-19 from people's perceptions.

This study solely contributes to investigate the role of creative social media use in preventing the Covid-19 outbreak incorporating the mediating effect of the knowledge of Covid-19 precautions online in Bangladesh. There is a large gap in the previous studies in examining the relationship between creative social media use, knowledge of Covid-19 precautions online and Covid-19 prevention. Besides, this study attempts to consider the educational level of the people as the indicator, which distinctively influences all the variables (predictors and dependent) used in the study. This sort of technique in using people's educational level as the control variable is hardly found in earlier studies (Ahmad and Murad 2020; Bodrud-Doza et al. 2020; Hossain et al. 2020; Islam, Barna et al. 2020a, b, c, d). These studies on the Covid-19 pandemic conducted in Bangladesh are also of sharp deficiency in utilizing the structural equation modeling (SEM) approach. To the best of our knowledge, this is the first study that has established the assumed creative role of social media in Covid-19 prevention through empirical investigation in the context of Bangladesh.

The rest of the paper is organized as follows: Sect. 2 describes the review of pertinent literature, Sect. 3 discusses theoretical framework, Sect. 4 delineates research hypotheses, Sect. 5 expounds research methods, Sect. 6 represents the results and relevant discussions, and Sect. 7 concludes with some policy recommendations. 


\section{Review of literature}

At present, social media platforms are usually used as faster and useful tools for hunting, sharing and dispensing health-related messages among the mass people (Zhao and Zhang 2017). Social media provides significant unofficial data sources to discover health information, which is not noticed to doctors or health division and to disclose the contexts on any life-threatening health matters (Charles-Smith et al. 2015). Besides, Medicare institutes and professional doctors massively utilize social media for guiding their patients and preventing any outbreak of a pandemic. Different pages of Facebook, Twitter and YouTube are opened by many hospitals, public physicians and health organizations for ensuring the congenial access of the patients to their sites with relevant healthcare information (Bender et al. 2013). As one of the key sources of information, social media platforms are considered the most comprehensively used and easiest accessible devices among users all over the world. More importantly, these tools are very effective to disseminate knowledge and information concerning sports, diseases and natural calamities aside from other events as greatly searched by the individual social media users (González-Padilla and Tortolero-Blanco 2020).

People necessitate timely access to authentic information concerning the symptoms of the disease and its immediate prevention while appearing a sudden epidemic (Bastani and Bahrami 2020). As the powerful tool of gathering disease-related information, Li et al. (2020) explored that social media use has a pivotal role in the awareness of Chinese people relating to Covid-19 cases by 10-14 days of its inception. The authors of this study opined that there is a correlation between the search of the internet and social media networks and the incidence of disease, i.e., Covid19 pandemic. Another study by Brooks et al. (2020) stated that social media platforms help maintain a relationship with family, friends, and kith and kin in easing isolation and dullness that is highly connected with anxiety and long-standing distress. Hence, their study recommends the use of social media during isolation to reduce the psychological effect.

Amid the pandemic, social media platforms are characterized by their brisk diffusions of different protocols at local, national and international spheres. It plays an important role in maintaining diverse procedures including Covid-19 treatment, protection of personal equipment or even suggestion for proper distribution of scant medical resource arrangements and bringing them in the state of new normal (Emanuel et al. 2020). Despite minor capacities, the medical centers and hospitals have developed different protocols at an adequate pace and execute or adjust other procedures to their respective circumstance or resources in their best possible time. Medical centers' such status and resource management strategy were beyond thinking 20 years ago when the social media platforms had not been originated (González-Padilla and Tortolero-Blanco 2020). The UK Nursing and Midwifery Council issued instructions relating to social media use that is called "the supplement to professional principles" emphasizing the proper utilization of social media and social sites of networking (Sahni and Sharma 2020). Thus, the use of creative social media in different countries is used with special consideration and dedication during the Covid-19 outbreak.

Apart from the creative use of social media, these media platforms have a problematic use amid the Covid-19 pandemic, which largely set the general people in the state of tremor. The World Health Organization (WHO) expressed their dissatisfaction that they along with the governments of different countries have been combating not only the brisk spread of the Covid-19 epidemic but also the infodemic of social media disclosures. Many media platforms notice that the pandemic is believed to be the first "infodemic" expressed via social media in which propaganda, chitchats and fake information have been growing more rapidly than the outbreak occurred. This has also been stimulating convulsions, miseries and tremor among the people (Hao and Basu 2020). Radwan et al. (2020a, b) studied how social media generate fear of Covid-19 among the students of primary and secondary school levels in the Gaza Strip, Palestine. The study findings divulge a significant effect of social media spreading tremor among the students, which have an adverse consequence on the mental health and psychological well-being of these school-going students.

González-Padilla and Tortolero-Blanco (2020) analyzed the effect of social media at the time of the Covid-19 outbreak, and this study substantially found a positive, negative and information correction use of social media disclosures. More importantly, the risky situation, e.g., dissemination of fabricated knowledge and perception, news and views, rumors, worrywart information relating to quarantine emanated from social media use that contributes to adversely affecting individuals' mental health. Shimizu (2020) considered social media use a serious threat to public life as these media platforms spread stress, tremor and shock in society. Moreover, these types of untrue and racial propaganda have brought patients to a critical condition in many countries. The studies of Mian and Khan (2020) and Ahmad and Murad (2020) provided a proof of the spread of fake news, falsified information, rumors on social media concerning Covid-19, and they mainly attempted to explain this problematic use of social media amid the Covid-19 pandemic in the light of conspiracy theory and the emergence of a novel virus. Ni et al. (2020) recommended utilizing social media for adopting the telemedicine approach and forbade wasting 
more time to avoid the spread of informedic and falsified information on social media disclosures.

Although there is a large body of scientific studies on the role of creative social media in Covid-19 prevention in the context of different countries, it is almost scarce in Bangladesh. Despite this, some quasi-relevant studies exist in Bangladesh highlighting the problematic use of social media and its consequence on the psychological factors of human life. For example, Lin et al. (2020) utilized probable psychopathology in identifying the relationship between awkward use of social media, insomnia and psychological distress in Bangladesh. This study explored a more likely psychological distress and insomnia of the people as occurred due to the Covid-19 epidemic. Islam et al. (2020a, b, c, d) examined the correlation between problematic internet use (PIU), and lifestyle and online activities among Bangladeshi youth and adults in the time of the Covid-19 pandemic. The study findings depicted that PIU positively impacts the lifestyle of the younger generation "having a higher level of education, living with a nuclear family, engaging in less physical exercise, avoiding household chores, playing online videogames, social media use and engaging in recreational online activities".

The above review of literature marks the use of social media not only for creative productions for Covid-19 prevention but also for destructive functions on mental health. The pieces of literature support the creative role of social media in the prevention of Covid-19, which attempts to establish the creative production of social media informing the public to adopt precautionary measures and use supplementary equipment and increase knowledge about the pandemic. On the other hand, problematic social media use produces fake news, views and information to pose a threat to people's life amid the Covid-19 pandemic. In addition, there exist a large number of studies in different developing and developed countries to focus on the role of creative social media to prevent the Covid-19 outbreak, which is very scarce in the context of Bangladesh. The Covid-19-related studies in Bangladesh perspective mainly highlight the psychological issue as experienced by the individuals during the pandemic. Our study thus adds value to the existing works of literature in investigating the creative role of social media though we have ignored the problematic use of these media platforms in this study.

\section{Theoretical framework: creative social media use, people's knowledge and Covid-19 prevention}

Generally, creative social media use is perceived through the scale of gratification as achieved by the people using this media platform (social media). Whiting and Williams
(2013) established his gratification theory of social media (SM) use and he stated, "people are drawn to SM to meet specific needs; when these needs are met, they feel gratification". Higher the creative use of social media, the higher the level of users' gratification. The sharing knowledge, expression of opinions and social interaction of the people are positively influenced by the social media use to develop creativity, novel ideas and hence act. This positive attainment of the people via social media employment is called creative social media use (Acar et al. 2019). Social media use is of three kinds including seeking information, maintenance and development of interaction, and creative outcome. People are well-acquainted with these phenomena from the perspective of diverse motivations, requisite knowledge/skill and satisfaction after the use of social media (Ekström and Östman 2015; Eynon and Malmberg 2011; Livingstone et al. 2005; Shah et al. 2001).

The people intending to gather information, i.e., information users utilize social media platforms to satisfy the solid goal of looking for guidance and knowledge for their own. Social media always provides up-to-date information flow as well as diverse views. Through this process, people can easily and speedily access the stream of information and also reach the broad spectrum of information, which is not achieved using conventional website pages (Ekström and Östman 2015). These users are supposed to be enriched with skills in determining, appraising and choosing information (Beaudoin 2008). Users' inquisitions and requirements are acquired through the information obtained from social media (Ruggiero 2000). On the other hand, the people wishing to maintain interaction, i.e., interaction users utilize social media in fulfilling their key motive of communication. For this, social media contains user-friendly appliance and mobile tools for eliminating mechanical difficulties and offers flexible access for users' expected interaction (Ekström and Östman 2015). In this case, these users need not have any special knowledge. Interaction users are handily kept in touch with the people of common interest by connecting through social media. Finally, creative users' eagerness for exposure makes them disseminating information and statements by utilizing diverse types of creative art such as music, write-ups, videos and games (Ekström and Östman 2015). The creative users are very much intended to draw attention to others, establish their name and fame and shift to leadership positions by their online publication of different works. In this respect, creative users require to be skilled with computer knowledge, compassion to issues in diverse areas and a particular stage of creativity (Eynon and Malmberg 2011). Apart from computer skills, social media applications for creative production are substantially proliferated with the use of powerful Smartphone and many other mobile technologies (Yadav et al. 2015). 
Fig. 1 Theoretical framework of the creative social media use and Covid-19 prevention. Note: Nodes denote the variable names and arrows represent the relationship among the variables



Relevant knowledge, as well as messages relating to public health, is gathered through creative social media platforms (Gough et al. 2017). People rely on these media disclosures to get information and facts about Covid-19 (Cellan-Jones 2020). Creative social media offers everybody the scope to convey messages with everybody else so that the posted documents on social media can inform the users of something about Covid-19 (Ahmad and Murad 2020). Aside from conventional contacting methods, the social mediadriven dissemination process utilizing social networks may present the information in a distilled and workable way and helps reach the well-organized free open-access learning materials ( $\mathrm{Ng}$ et al. 2020). Even free open-access medical education (FOAM) could be achieved freely and effectively through the creative use of social media (Chan et al. 2020). Moreover, the role of creative social media during Covid-19 is information-based, encompassing the infection scenarios in different countries, precautionary measures to be adopted and scale of disease prevention to be achieved, etc. (Depoux et al. 2020). It plays an important role in maintaining diverse procedures including Covid-19 treatment, protection of personal types of equipment or even suggestions for proper distribution of scant medical resource arrangements and bringing them in the state of new normal (Emanuel et al. 2020). From the above conceptual discussions, we develop the theoretical model for investigation represented in Fig. 1.

\section{Research hypotheses}

Theories and empirical shreds of evidence support the nexus between creative social media use and Covid-19 prevention. As people adopt Covid-19 precautions-related information/ knowledge online through using social media, this knowledge becomes favorable for preventing Covid-19 outbreak. Besides, people's level of education boosts up creative use of social media, knowledge of Covid-19 precautions online and Covid-19 prevention. Education makes people aware of their academic necessities and socio-cultural responsibilities. Comparatively, higher learning people become more conscious and liable to society and societal problems like the Covid-19 outbreak. Besides, pandemic-induced obstruction such as quarantine leads these educated people to be more connected with the internet especially social media platforms for reading academic instruments and gaining Covid-19-related knowledge (Al-Dossary et al. 2020). These responsibility-prone people also come to a higher connection with social media outlets in serving societal people by providing them necessary information about the Covid-19 outbreak and preventing this pandemic. Moreover, the activities concerning fellow feelings and social service more or less depend on the level of people's education (Yanti et al. 2020). Thus, the educational level of the people becomes a significant determinant in stimulating the creative use of social media, creative users' knowledge of Covid-19 precautions and Covid-19 prevention. Following hypotheses are set for conducting this study:

$H_{1}$ Creative social media use stimulates knowledge of Covid-19 precautions online.

$\mathbf{H}_{2}$ Knowledge of Covid-19 precautions online impacts Covid-19 prevention.

$\mathrm{H}_{3}$ Knowledge of Covid-19 precautions online mediates the nexus between creative social media use and Covid-19 prevention.

$\mathbf{H}_{4}$ People's educational level affects creative social media use.

$\mathrm{H}_{5}$ People's educational level impacts knowledge of Covid19 precautions online.

$H_{6}$ People's educational level helps prevent the Covid-19 outbreak.

\section{Methods}

\subsection{Procedure}

As the significant category of the non-probability sampling method, the purposive sampling technique is utilized in this study. We cover the people who use the internet as well as social media platforms (e.g., Facebook, YouTube, WhatsApp, Imo, Twitter, LinkedIn, WeChat and Instagram) to collect information for this study. This purposive 
sampling procedure encompasses "an iterative process of selecting research subjects rather than starting with a predetermined sampling frame" (Robinson 2014). Similar to grounded theory, the sample determination process is closely associated with the exploration of theme, theory and factors via examination and evidence. In this case, special significance is given to each sampling instrument holding a distinctive place concerning the research undertaking (Schutt 2018). From this point of view, this study uses a purposeful sampling technique to choose respondents based on their definite knowledge about the goal of empirical inspection. In this case, the utilization of the random sampling technique is not possible (Williamson 2002). On the other hand, the answers of the respondents to the survey questionnaire are voluntary. Also, the study was conducted during the lockdown and quarantine (home and institutional) period that keeps the researchers away from reaching the general people physically. Therefore, this study keeps samples limited to internet users only. Moreover, being a cost-effective and less time-consuming procedure, these researchers conveniently select this sampling technique. There is evidence of empirical literature (Al Zubayer et al. 2020; Bodrud-Doza et al. 2020; Ferdous et al. 2020; Hossain et al. 2020; Islam, Barna et al. 2020a, b, c, d; Islam, Bodrud-Doza et al. 2020a, b, c, d; Hossain et al. 2020), which applied purposive sampling technique to work on Covid-19 outbreak in Bangladesh in collecting people's opinions. Using this technique, we invite the respondents to complete the "Google Questionnaire Form" online via Emails, Messengers (Facebook) and WhatsApp. Respondents' demographic information such as gender, age, education, occupation, marital status and family size are considered. To minimize the concern of data leakages, we confirm the respondents not to use their information in any other purpose except research end and these data will be demolished after use. The study period is spanned from June to October 2020, which is just before the second wave of the Covid-19 outbreak in Bangladesh.

\subsection{Sample}

The study mainly considers the people from Bangladesh whose ages are ranged from 18 to 61 and the average age of the respondents are 27.18 years (standard deviation and median are 8.37 and 24 , respectively). The study undertakes 265 people as respondents who participated in a self-administered online survey designed. In the survey, $75.47 \%$ male and $24.53 \%$ female participates and $56.98 \%$ of total respondents are students. The education levels of the respondents include Honors (41.13\%), Masters (41.13\%) and $\mathrm{PhD}(3.77 \%)$. Descriptive statistics of respondents are exhibited in Table 1.
Table 1 Demographic characteristics of the respondents $(N=265)$

\begin{tabular}{|c|c|c|c|c|}
\hline Qualitative variables & Percentage & & & \\
\hline \multicolumn{5}{|l|}{ Gender } \\
\hline Male & 75.47 & & & \\
\hline Female & 24.53 & & & \\
\hline \multicolumn{5}{|l|}{ Education level } \\
\hline Secondary & 0.75 & & & \\
\hline Higher secondary & 13.21 & & & \\
\hline Honor's & 41.13 & & & \\
\hline Masters & 41.13 & & & \\
\hline $\mathrm{PhD}$ & 3.77 & & & \\
\hline \multicolumn{5}{|l|}{ Marital status } \\
\hline Unmarried & 65.66 & & & \\
\hline Married & 34.34 & & & \\
\hline \multicolumn{5}{|l|}{ Occupation } \\
\hline Student & 56.98 & & & \\
\hline Govt. employee & 11.70 & & & \\
\hline Non-govt. employee & 19.62 & & & \\
\hline Doctor/nurse/health professional & 1.89 & & & \\
\hline Business/self-employed & 5.66 & & & \\
\hline Unemployed & 4.15 & & & \\
\hline Quantitative variables & Average & SD & Range (Max-Min) & Median \\
\hline Age & 27.18 & 8.37 & $43(61-18)$ & 24 \\
\hline Family size & 4.86 & 1.96 & $13(15-02)$ & 04 \\
\hline
\end{tabular}




\subsection{Measures}

\subsubsection{Creative social media use}

Considering a variable namely creative social media use, the study sets seven types of activities performed by the individual internet users on social media. These seven kinds of activities are exhibited in four broad heads including (a) reading essays/writings, (b) seeing photos and flyers, (c) watching videos (d) posting writings, pictures, flyers and videos on social media platforms like Facebook, WhatsApp and YouTube. We analyze these seven activities under four measures/items based on the contents and formats of these activities to more widely estimate the creative usages of social media. The users read, watch and post writings, pictures, flyers and videos on these media disclosures. Respondents are mainly questioned to notice how often they use creative social media for performing these seven categories of creative functions on a 5-point Likert scale spanning from 1 (never) to 5 (very often).

We measure the questionnaire's internal consistency by utilizing Cronbach's Alpha test for this variable. The value of the test shows 0.83 that established the reliability of each of the items under definite variable used in the survey questionnaire. Besides, we also perform confirmatory factor analysis (CFA) for this variable (creative social media use) whose results suffice the fitness of the data used in the model $\left[\chi^{2}[02, N=265]=14.517\right.$ ( $p$-value: $0.001), \mathrm{CFI}=0.972$ (very closer to 1.00$), \mathrm{TLI}=0.916$ (very closer to 1.00 ), $S R M R=0.052$ (implies fair fit) and RMSEA $=0.154$ (implies good fit)]. To check the measurement of the model, the factor loadings of this variable (creative social media use) are tested and displayed in Table 2. The values of factor loadings closer to 1 indicate the strong influence of the factors/items on the variable. The scores of all factors are saved for the main estimation.

\subsubsection{Knowledge of Covid-19 precautions online}

We measure the knowledge of Covid-19 precautions online across eleven components that include (a) washing hand, (b) wearing the mask, (c) maintaining social distance, (d) touching case sensitive organs (e.g., mouth, nose, eyes and ears), (e) washing clothes after returning home, (f) avoiding mass gathering, $(\mathrm{g})$ helping people amid the pandemic, (h) old care, (i) infected areas, (j) infected persons and (k) Covid-19 symptoms.
Table 2 Creative social media use

Table 3 Knowledge of Covid19 precautions using social media

\begin{tabular}{lcc}
\hline Items & Mean (SD) & Factor loadings \\
\hline How often do you utilize social media disclosures such & as & Facebook, Twitter, WhatsApp, YouTube etc.?: \\
Reading essays/writings on social media & $3.38(0.99)$ & 0.78 \\
Seeing photos/flyers on social media & $3.33(0.94)$ & 0.80 \\
Watching videos on social media & $3.18(0.96)$ & 0.80 \\
Posting writings/pictures/flyers/videos on social media & $2.29(1.03)$ & 0.57 \\
\hline
\end{tabular}

Responses denote very often $=5$, often $=4$, sometimes $=3$, seldom $=2$ and never $=1$

$S D$, standard deviation

\begin{tabular}{lcc}
\hline Items & Mean (SD) & Factor loadings \\
\hline Do you read/watch any of the following as content & (post/writing/picture/video) & on social media? \\
Washing hand & $3.07(1.11)$ & 0.75 \\
Wearing mask & $3.09(1.11)$ & 0.75 \\
Maintaining social distance & $3.22(1.10)$ & 0.80 \\
Touching mouth/nose/eyes & $3.14(1.06)$ & 0.81 \\
Washing clothes after returning home & $3.04(1.13)$ & 0.76 \\
Avoiding Mass gathering & $3.33(1.10)$ & 0.81 \\
Helping people amid the pandemic & $3.42(0.99)$ & 0.68 \\
Old care & $3.31(1.04)$ & 0.74 \\
Infected areas & $3.23(1.06)$ & 0.75 \\
Infected persons & $3.14(1.05)$ & 0.69 \\
Covid-19 symptoms & $3.38(1.01)$ & 0.68 \\
\hline
\end{tabular}

Responses denote very often $=5$, often $=4$, sometimes $=3$, seldom $=2$, never $=1$

$S D$, standard deviation 
We consider these items under one variable, i.e., knowledge of Covid-19 precautions online to know about the level of information relating to Covid-19 virus among individual social media users. These items are formed utilizing a 5-point Likert scale ranging from 1 (never) to 5 (very often) on which respondents opine. The internal consistency or reliability of the questionnaire for this variable is also measured using Cronbach's Alpha test, which is 0.93 , confirming the reliability of the respective items set under specific variable in the survey questionnaire (Table 3). The model data fitness is also checked by the CFA outcomes: $\left(\chi^{2}[44, N=265]=339.035\right.$ ( $p$-value: $\left.<0.001\right), \mathrm{CFI}=0.851$ (closer to 1.00$), \mathrm{TLI}=0.814$ (closer to 1.00$), \mathrm{SRMR}=0.075$ (implies good fit) and RMSEA $=0.159$ (implies good fit)). Factor loadings of this variable, i.e., knowledge of Covid-19 precautions online are also estimated for the measurement of the model, which are exhibited in Table 3.

\subsubsection{Covid-19 prevention}

Covid-19 prevention is estimated by seven online activities that are done by using social media. These activities cover (a) awareness of Covid-19 spread, (b) wearing the mask at outside, (c) frequent hand washing, (d) precaution before touching the face, nose and eyes, (e) avoiding gathering, (f) maintaining physical/social distances and (g) knowing Covid-19 symptoms.

We set one variable along with its seven items in which participants are questioned to respond on a 5-point Likert scale ranging from 1 (definitely not) to definitely (5). For checking the questionnaire's reliability for this variable, Cronbach's Alpha value is then estimated, which is 0.80 . It implies that the questionnaire is internally consistence to run a regression model for this study (Table 4). The data fitness of the model for this variable is also proven by the CFA results: $\left(\chi^{2}[14, N=265]=94.44\right.$ ( $p$-value: $\left.<0.001\right)$, $\mathrm{CFI}=0.863$ (closer to 1.00$), \mathrm{TLI}=0.794$ (closer to 1.00 ), $\mathrm{SRMR}=0.074$ (implies good fit) and $\mathrm{RMSEA}=0.147$ (implies good fit)). The results of the factor loadings of this variable (Covid-19 prevention) are reported in Table 4.

\subsubsection{Educational level}

This study considers respondents' education level as the control variable that separately influences the creative social media use, Covid-19-related knowledge online and Covid19 prevention. People at a higher level of education are relatively more prone to using social media especially for disseminating information to serve the people during any crisis (Yanti et al. 2020), which has significant relevance to add this variable (educational level) to the study model. On the other hand, this study considers the educated people who usually use social media platforms and have the proper knowledge to fill up the Google questionnaire form provided for their responses. As there is a significant role of people's education level in using social media and disseminating knowledge via social media for both the self-regarding and other-regarding services for Covid-19 prevention, this study exclusively adopts this variable into the SEM model apart from age, gender, family size, occupation and marital status. This study has a more sensibility orientation in which other demographic characters except for the educational status of the people (respondents) might be more workable. Besides, more conscious people with their definite educational status do beyond normality for serving the society as well as people. Lastly, the homogenous character of the respondents (e.g., all are educated) is measured by their educational status in the study. All these points validate adopting people's educational level into the model apart from other demographic features. Respondents with five levels of the educational degree including secondary, higher secondary, Honors, Masters and $\mathrm{PhD}$ with their respective scores 1, 2, 3,4 and 5, respectively, are considered and executed in the study model.

Table 4 Covid-19 prevention

\begin{tabular}{lll}
\hline Items & Mean (SD) & Factor loadings \\
\hline Do you agree or disagree with the following statements? & & \\
I am aware of Covid-19 spread & $4.86(0.41)$ & 0.51 \\
I wear a mask while going outside & $4.90(0.37)$ & 0.57 \\
I wash hand frequently & $4.81(0.55)$ & 0.80 \\
I take precaution before touching mouth, nose and eyes & $4.62(0.77)$ & 0.73 \\
I avoid any mass gathering & $4.68(0.88)$ & 0.58 \\
I maintain physical distance & $4.66(0.67)$ & 0.67 \\
I know the Covid-19 symptoms & $4.74(0.58)$ & 0.44 \\
\hline
\end{tabular}

Responses denote definitely $=5$, probably $=4$, possibly $=3$, probably not $=2$, definitely not $=1$ $S D$, standard deviation 
Table 5 Correlations among the key variables' factor scores

\begin{tabular}{llll}
\hline Variables & 1 & 2 & 3 \\
\hline $\begin{array}{l}\text { Creative social media use } \\
\begin{array}{l}\text { Knowledge of Covid-19 pre- } \\
\text { cautions online }\end{array}\end{array}$ & $0.57^{* * *}$ & 1.00 & \\
\begin{tabular}{l} 
Covid-19 prevention \\
\hline
\end{tabular} & $0.23^{* * *}$ & $0.21 * * *$ & 1.00 \\
\hline
\end{tabular}

$\mathrm{N}=265$

$* * * p<0.01$

\subsection{Data analysis}

Attrition analysis in the case of some items under a particular construct (variable) is carried out to improve the values of $\boldsymbol{\alpha}$ tested in the study. This helps determine the consistency and reliability of the survey questionnaire. For each variable, confirmatory factor analysis (CFA) is executed to check the fitness of the specific model data. CFA is the pre-diagnosed part of the structural equation modeling (SEM) approach, which helps examine the causal association between latent and observed variables (Mueller and Hancock 2001). This a priori specified technique represents a measurement model based on SEM (Fontaine 2005). Correlations among the items of the variables are tested and noticed in Table 5. Besides, factor loadings to measure the models of all variables constructed based on different items with a Likert scale are estimated for the final model analysis. Then, we employ the structural equation modeling (SEM) approach in this study. SEM is one of the commanding multivariate data estimation technique used progressively more in empirical studies to check and assess multivariate causal associations among the variables of interest. This method varies from other estimation technique due to SEM's exploration of the direct and indirect influences of predictor variables on the dependent variable as assumed (Fan et al. 2016). More specifically, SEM is a technique of estimation that is capable of handling a good amount of endogenous and exogenous indicators as well as latent (unobserved) variables, which are estimated as linear permutations of measurement (observed) indicators (Jenatabadi and Ismail 2014). By utilizing the SEM approach, this study investigates total, direct and indirect effects of the predictor variables (creative social media use, knowledge of Covid-19 precautions online, education level) on the dependent variable (Covid-19 prevention) (Table 6). As a post-estimation technique, we represent the results of Comparative Fit Index (CFI), Tucker-Lewis Index (TLI) and root mean square error of approximation (RMSEA) for the authentication of the model used in the study (Table 6).

\section{Results and discussions}

Attrition analysis does not find out any significant difference among the items of the variables in terms of the values of factor loadings. This also implies that omitting some items/factors from the variables produces no negative value among the scores of factor loadings in the correlation analysis. Table 5 shows the correlations among the key variables' factor scores and focuses on the positive and highly significant correlations among the variables.

We properly explain and assess the theoretical model devoid of any adjustment by using the indices of modification. Mainly, the study using structural equation modeling (SEM) approach explores the total, direct and indirect effects of the predictor variables, e.g., creative social media use and knowledge of Covid-19 precautions online and the control variable, e.g., educational level of the people on the dependent variable, e.g., Covid-19 prevention in the context of Bangladesh. The results are depicted in Table 6 and Fig. 2 (Appendix).

The estimated results specifically divulge that creative social media use has a significantly positive and indirect effect on Covid-19 prevention, whereas knowledge of Covid19 precautions online mediates this nexus between creative social media use and Covid-19 prevention (Table 6). It also implies that creative use of social media boosts the knowledge of Covid-19 precautions online $(0.667, \mathrm{p}<0.01)$, and this relevant knowledge ultimately helps prevent the Covid-19 pandemic $(0.052, p<0.01)$ in Bangladesh. In the time of the Covid-19 pandemic, social media has provided greater advantages for the circulation of various learning contents and materials for the users and different authorities concerned. For instance, different infographics have been developed relating to patients' management with suspected or confirmed cases of Covid-19, and this knowledge and information have translated to different languages and shared and distributed to the relevant areas of concern (GonzálezPadilla and Tortolero-Blanco 2020). Quicker circulation of knowledge about Covid-19 precautionary measures has myriads of importance. A novel study conducted by Basch et al. (2020a, b) assessed the widely viewed 100 video clips with the word 'Covid-19' on YouTube. Among these, one-third of video clips are much concerned with preventive measures, less than half with the most recurring symptoms and about $90 \%$ with anxiety, quarantine and deaths.

Even imparting evidence-based literature on social media platforms has been increased via large numbers of download, queries and citations of the articles on the Covid-19 pandemic. Thus, rapid dissemination of knowledge has been a key to preventing any crisis worldwide (Eysenbach 2012). As this creative use of social media is proven in the different parts of the world, medical practitioners and state 
Table 6 Total, direct and indirect effect in SEM analysis

\begin{tabular}{|c|c|c|c|}
\hline Causal relationship & $\begin{array}{l}\text { Total } \\
\text { effect }\end{array}$ & Direct effect & Indirect effect \\
\hline Creative social media use $\rightarrow$ Covid-19 prevention & $0.034 * * *$ & $\mathrm{NP}$ & $0.034 * * *$ \\
\hline Creative social media use $\rightarrow$ Knowledge of Covid-19 precautions online & $0.667 * * *$ & $0.667 * * *$ & NP \\
\hline Knowledge of Covid-19 precautions online $\rightarrow$ Covid- 19 prevention & $0.052 * * *$ & $0.052 * * *$ & NP \\
\hline Educational level $\rightarrow$ Covid-19 prevention & $0.046 * *$ & $0.043 * *$ & 0.003 \\
\hline Educational level $\rightarrow$ Creative social media use & 0.088 & 0.088 & NP \\
\hline Educational level $\rightarrow$ Knowledge of Covid-19 precautions online & 0.050 & -0.009 & 0.059 \\
\hline RMSEA & $0.098(0.05-0.10$ implies fair fit $)$ & & \\
\hline CFI & 0.827 (Closer to 1.00$)$ & & \\
\hline TLI & $0.806($ Closer to 1.00$)$ & & \\
\hline SRMR & $0.072($ SRMR $<0.08$ implies good fit $)$ & & \\
\hline
\end{tabular}

$N P$, No path; RMSEA, Root mean squared error of approximation; CFI, Comparative fit index; TLI, Tucker-Lewis index; SRMR, Standardized root mean squared residual

p-value: $* * *<0.01, * *<0.05, *<0.1$

authorities suggest following social media guidelines as preventive measures of Covid-19. However, they emphasize that the information and knowledge adopted through social media must be gathered by the authenticated professional blocks and communication clusters. Besides, social media platforms have been conducting different coordinated research projects, surveys and other cutting-edge studies to provide evidence-based knowledge to the public. Moreover, medical knowledge via live programs and recorded webinars have been instrumental in the prevention of the Covid-19 pandemic (González-Padilla and Tortolero-Blanco 2020).

This investigated results (Table 6) are similar to the studies of González-Padilla and Tortolero-Blanco, (2020); Bhagavathula et al. (2020); Gray et al. (2020); Ferdous et al. (2020); Lancet (2020); Lohiniva et al. (2020); Rzymski and Nowicki (2020); Khasawneh et al. (2020) and Basch et al. (2020a, b). These authors emphasize that creative use of social media helps all segments of people, i.e., general mass, patients, students and kids in schools to be informed of Covid-19 precautions online, which finally induces Covid19 prevention. On the other hand, our study findings are incoherent with Srivastava et al. (2020); Islam, Sarkar, et al. (2020a, b, c, d); Tasnim et al. (2020); Naeem et al. (2020); Soltaninejad (2020) and Lin et al. (2020) who highlight that social media use fuels the rush of enormous rumors, misinformation, hoaxes relating to virus prevention, etiology, cure and consequences. These types of misinformation promote wrong human behaviors that resulted in the spread of the virus and unpredicted mental and physical health effects.

The examined results also indicate that the educational level of the people positively and insignificantly impacts the use of social media (0.088) and positively and significantly affects Covid-19 prevention $(0.046, \mathrm{p}<0.05)$. On the other hand, there is an insignificant and negative effect of the people's educational level on the knowledge of Covid19 precautions, which is achieved using online platforms (Table 6). The educational level of the people has a favorable role in preventing any disease or virus-like Covid-19 pandemic because education urges people to keenly understand the facts and formations of the problem. This also allows a reader or researcher to study valuable materials like books, articles and research reports. Besides, a deep understanding of a critical issue is not possible without a higher level of education. Thus, pandemic prevention is more or less dependent on the learners with academic and professional degrees having deeper knowledge. The positive effect of the educational level of the respondents on Covid-19 prevention as found in our study is supported by Yanti et al. (2020) and Al-Dossary et al. (2020) who establish that knowledge of an individual hails from teaching and training, which are largely influenced by the level of education of an individual and community. Moreover, education builds awareness among individuals and communities by providing knowledge as well as information.

We perform the following diagnostic or post-estimation tests: $\left[\left(\chi^{2}[226, \mathrm{~N}=265]=800.43(p\right.\right.$-value: $<0.001)$, $\mathrm{CFI}=0.827$ (closer to 1.00 ), $\mathrm{TLI}=0.806$ (closer to 1.00 ), SRMR $=0.072(<0.08$ implies good fit $)$, RMSEA $=0.098$ (0.05-0.10 implies fair fit)]. All these results of the diagnostic tests confirm the goodness of fit of the model as well as the study results obtained from the SEM analysis (Table 6).

The findings obtained from the SEM analysis show that $\mathrm{H}_{1}, \mathrm{H}_{2}, \mathrm{H}_{3}$, and $\mathrm{H}_{6}$ are supported and $\mathrm{H}_{4}$ and $\mathrm{H}_{5}$ are rejected in the study outcomes (Table 7). Hence, the outcomes of the study establish that creative social media use helps prevent Covid-19 pandemic and this relationship between creative social media use and Covid-19 prevention is mediated by the knowledge of Covid-19 precautions as obtained from 
Table 7 Summary of the research hypotheses and its outcomes

\begin{tabular}{lll}
\hline Hypotheses & Statement & Outcome \\
\hline $\mathrm{H}_{1}$ & Creative social media use stimulates knowledge of Covid-19 precautions online & Supported \\
$\mathrm{H}_{2}$ & Knowledge of Covid-19 precautions online impacts Covid-19 prevention & Supported \\
$\mathrm{H}_{3}$ & Knowledge of Covid-19 precautions online mediates the nexus between creative & Supported \\
& social media use and Covid-19 prevention & \\
$\mathrm{H}_{4}$ & People's educational level affects creative social media use & Rejected \\
$\mathrm{H}_{5}$ & People's educational level impacts knowledge of Covid-19 precautions online & Rejected \\
$\mathrm{H}_{6}$ & People's educational level helps prevent the Covid-19 outbreak & Supported \\
\hline
\end{tabular}

an online platform. On the other hand, people's education level is a key to preventing the Covid-19 outbreak whereas creative use of social media and knowledge of Covid-19 precautions online are not impacted by the educational level of the people in Bangladesh. This is because of the abysmal use of social media by people from all sects whether they are educated or uneducated.

\section{Conclusion and policy recommendations}

This study performed an online-based survey among people at different ages in Bangladesh during June-October 2020. This paper mainly addresses the existing gap in the literature on the nexus between the creative use of social media and Covid-19 prevention by checking the mediating role of online-based knowledge of Covid-19 precautions. Previous studies mainly highlighted the role of social media on Covid-19 prevention in the perspective of different countries. But no study considered the mediating effect of the knowledge of Covid-19 precautions online to test the association between creative use of social media and Covid-19 prevention in Bangladesh and beyond.

Our findings divulge that involving in the creative use of social media enhances the likelihood of Covid-19 prevention by improving online-based knowledge of Covid-19 precautions. The results point out that the creative use of social media can promote the possibility of preventing the Covid-19 pandemic in Bangladesh through the knowledge of Covid-19 precautions online. The study findings also discover the positive role of the people's educational level in the prevention of Covid-19. This outcome proffers the government of Bangladesh to enter into a state of policy to promote the strategies of Covid-19 prevention by encouraging creative production online, especially social media use. This will invariably spur the knowledge of Covid-19 precautions online. Before the arrival of the internet in people's daily life, a very few people as internet users were involved in creative production due to obstacles in technology use and high time cost. For a user-friendly application, social media platforms emerged as a change-maker to transform internet-based outcomes into a mass activity with their convenient access and a lower investment of time (Leung 2009). At this point, the government of Bangladesh should pursue appropriate policies in exploiting the potentials of creative social media use to deal with any type of crisis like the Covid-19 pandemic.

As the educational level of the people is supportive to prevent the Covid-19 outbreak, authority concerned can consider integrating the creative production in social media with learning and teaching gamut at every level of education to motivate young people. This might be a key policy intervention in using social media platforms for creative productions. Different pieces of training, workshops and short courses can act and eliminate technological obstacles for producing creative outcomes by using social media disclosures. Even social media education especially its use (creative use and misuse), operations, technological learning, cybersecurity laws on social media use, norms, ethical guidance should be incorporated in the academic curriculum at all-level educations in diverse disciplines.

Our main findings also depict the mediating role of online-based knowledge of Covid-19 precautions on the nexus between creative social media use and Covid-19 prevention. The higher motivation for the users is instrumental in utilizing social media for creative production apart from the problematic use of these media platforms. More specifically, all types of media disclosures (printing and online) and campaigning agencies/groups would be patronized by the relevant government departments to propagate the usefulness of social media platforms by presenting its cost-effectiveness, easiest entries, valuable and exclusive information and updated data and research-based findings for diverse fields and disciplines of people's life. Besides, the governmental appropriate policies for the proliferation of cybersecurity laws are mandatory for dealing with the misuse of social media that usually misguides the people. Although the creative use of social media is not an ultimate prerequisite for the prevention of the Covid-19 outbreak, lack of concentration on the use of these media platforms might hamper the ultimate goal of Covid-19 elimination in the days to come in Bangladesh. A recent study was done 
Fig. 2 Results of total, direct and indirect effect in SEM analysis

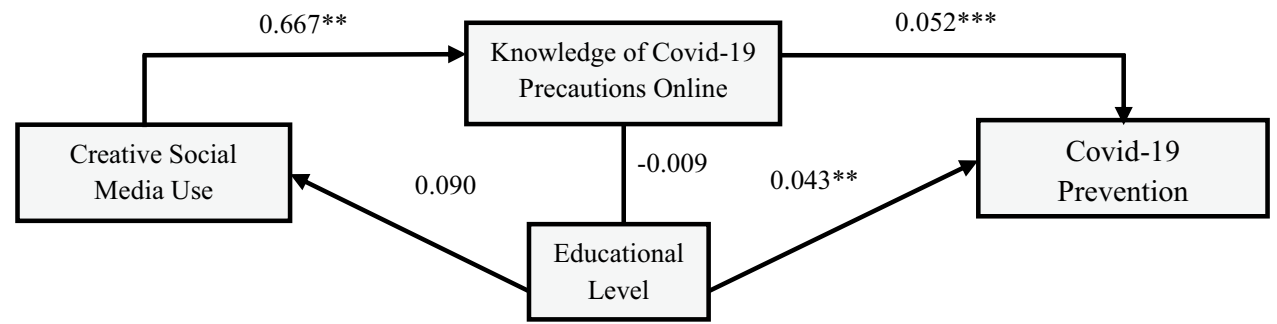

among 2017 respondents in Bangladesh which revealed that less than half (48.3\%) of people had more accurate knowledge regarding Covid-19 (Ferdous et al. 2020). More creative utilization of social media can help gather precautionary knowledge on Covid-19 for its elimination from Bangladesh.

Bangladesh as a recently graduated developing country from the least developed one has an aspirated goal of materializing its vision to be a developed economy by 2041 by emphasizing the development of technology as well as the digital sector. Through this, the policymakers of the country intend to increase the flows of technological apparatus usages like media, social media use to add people to the development process of the country. The policymakers also have a motive to develop two-way dissemination of information (e.g., from people to policymakers and vice versa) to inform people of both the tailback and development of the country and make the governments (policy domain) transparent and accountable to reach the spectacular growth trajectory. Therefore, policymakers should have the utmost intention to strengthen the scope of creative social media use for gathering precautionary knowledge online on any crisis such as the Covid-19 pandemic in order to prevent this outbreak in Bangladesh.

The study has some limitations. The data of this study are collected based on the purposive sampling technique, which is of a few drawbacks. This technique might produce unreliable and biased results. It also keeps the researchers away from generalizing the study findings. This requires a somewhat cautious consideration of the study findings. Despite findings-related generalization issue, this study based on the purposive sampling technique emphasizes the specific demographic characteristics of the population including education/educated people that belong to a particular share of those population who use social media platforms. Besides, utilizing the SEM approach needs at least 200 samples for factor loadings to confirm adequate sample taken in the model. Although the current study considers more than 200 samples, the inclusion of a more representative sample would strengthen the scope of further study by covering the face-to-face interview with diverse sects of people who use social media platforms across Bangladesh.

\section{Appendix}

See Fig. 2.

Funding The authors received no funding to conduct the research.

\section{Declarations}

Conflict of interest The authors declare that they have no competing interests.

Consent to participate Participants were informed about the survey and they willingly participated in the online survey.

\section{References}

Acar S, Neumayer M, Burnett C (2019) Social media use and creativity: exploring the influences on ideational behavior and creative activity. J Creat Behav 55(6):39-52

Ahmad AR, Murad HR (2020) The impact of social media on panic during the COVID-19 pandemic in Iraqi Kurdistan: online questionnaire study. J Med Internet Res 22(5):e19556

Al Zubayer A, Rahman ME, Islam MB, Babu SZD, Rahman QM, Bhuiyan MRAM, Khan MKA, Chowdhury MAU, Hossain L, Habib RB (2020) Psychological states of Bangladeshi people four months after the COVID-19 pandemic: an online survey. Heliyon 6(9): 05057

Al-Dossary R, Alamri M, Albaqawi H, Al Hosis K, Aljeldah M, Aljohan M, Aljohani K, Almadani N, Alrasheadi B, Falatah R (2020) Awareness, attitudes, prevention, and perceptions of COVID-19 outbreak among nurses in Saudi Arabia. Int J Environ Res Public Health 17(21):8269

Al-Zaman MS (2020) Healthcare Crisis in Bangladesh during the COVID-19 Pandemic. Am J Trop Med Hyg 103(4):1357-1359

Basch CH, Hillyer GC, Jaime C (2020a) COVID-19 on TikTok: harnessing an emerging social media platform to convey important public health messages. Int J Adolesc Med Health. https://doi.org/ 10.1515/ijamh-2020-0111

Basch CH, Hillyer GC, Meleo-Erwin ZC, Jaime C, Mohlman J, Basch CE (2020b) Preventive behaviors conveyed on YouTube to mitigate transmission of COVID-19: cross-sectional study. JMIR Public Health Surveill 6(2):e18807

Bastani P, Bahrami MA (2020) COVID-19 related misinformation on social media: a qualitative study from Iran. J Med Internet Res. https://doi.org/10.2196/18932 
Beaudoin CE (2008) Explaining the relationship between internet use and interpersonal trust: taking into account motivation and information overload. J Comput-Mediat Commun 13(3):550-568

Bender JL, Yue RYK, To MJ, Deacken L, Jadad AR (2013) A lot of action, but not in the right direction: systematic review and content analysis of smartphone applications for the prevention, detection, and management of cancer. J Med Internet Res 15(12):e287

Bhagavathula AS, Aldhaleei WA, Rahmani J, Mahabadi MA, Bandari DK (2020) Novel coronavirus (COVID-19) knowledge and perceptions: a survey on healthcare workers. MedRxiv 1:7

Bodrud-Doza M, Shammi M, Bahlman L, Islam ARMT, Rahman MM (2020) Psychosocial and socio-economic crisis in bangladesh due to COVID-19 pandemic: a perception-based assessment. Front Public Health. https://doi.org/10.3389/fpubh.2020.00341

Brooks SK, Webster RK, Smith LE, Woodland L, Wessely S, Greenberg N, Rubin GJ (2020) The psychological impact of quarantine and how to reduce it: rapid review of the evidence. The Lancet 395:912-920

Cellan-Jones R (2020) Tech tent: is social media spreading the virus. Retrieved 5(01):2020

Chan AKM, Nickson CP, Rudolph JW, Lee A, Joynt GM (2020) Social media for rapid knowledge dissemination: early experience from the COVID-19 pandemic. Anaesthesia 75:1579-1582

Charles-Smith LE, Reynolds TL, Cameron MA, Conway M, Lau EHY, Olsen JM, Pavlin JA, Shigematsu M, Streichert LC, Suda KJ (2015) Using social media for actionable disease surveillance and outbreak management: a systematic literature review. PLoS ONE 10(10):e0139701

Depoux A, Martin S, Karafillakis E, Preet R, Wilder-Smith A, Larson $\mathrm{H}$ (2020) The pandemic of social media panic travels faster than the COVID-19 outbreak. Oxford University Press, Oxford

Ekström M, Östman J (2015) Information, interaction, and creative production: The effects of three forms of internet use on youth democratic engagement. Commun Res 42(6):796-818

Emanuel EJ, Persad G, Upshur R, Thome B, Parker M, Glickman A, Zhang C, Boyle C, Smith M, Phillips JP (2020) Fair allocation of scarce medical resources in the time of Covid-19. Mass Med Soc. https://doi.org/10.1056/NEJMsb2005114

Eynon R, Malmberg L-E (2011) A typology of young people's Internet use: Implications for education. Comput Educ 56(3):585-595

Eysenbach G (2012) Correction: Can tweets predict citations? Metrics of social impact based on twitter and correlation with traditional metrics of scientific impact. J Med Internet Res 14(1):e7

Fan Y, Chen J, Shirkey G, John R, Wu SR, Park H, Shao C (2016) Applications of structural equation modeling (SEM) in ecological studies: an updated review. Ecol Process 5(1):1-12

Ferdous MZ, Islam MS, Sikder MT, Mosaddek ASM, Zegarra-Valdivia JA, Gozal D (2020) Knowledge, attitude, and practice regarding COVID-19 outbreak in Bangladesh: an online-based crosssectional study. PLoS ONE 15(10):e0239254

Fontaine JRJ (2005) Equivalence. Encycl Soc Meas 1:803-813

GlobalStat (2021) Social media stats in Bangladesh-January 2021. Statcounter. https://gs.statcounter.com/social-media-stats/all/ bangladesh

González-Padilla DA, Tortolero-Blanco L (2020) Social media influence in the COVID-19 pandemic. Int Braz J Urol 46:120-124

Gough A, Hunter RF, Ajao O, Jurek A, McKeown G, Hong J, Barrett E, Ferguson M, McElwee G, McCarthy M (2017) Tweet for behavior change: using social media for the dissemination of public health messages. JMIR Public Health Surveill 3(1):e14

Gray DJ, Kurscheid J, Mationg ML, Williams GM, Gordon C, Kelly M, Wangdi K, McManus DP (2020) Health-education to prevent COVID-19 in schoolchildren: a call to action. Infect Dis Poverty 9(1):1-3

Hao K, Basu T (2020) The coronavirus is the first true social-media "infodemic." In 2020-02-12].
Holmbom M (2015) The youTuber a qualitative study of popular content. Institutionen För Informatik, Umeå University.

Hossain T, Ahammed B, Chanda SK, Jahan N, Ela MZ, Islam N (2020) Social and electronic media exposure and generalized anxiety disorder among people during COVID-19 outbreak in Bangladesh: a preliminary observation. PLoS ONE 15:1-13. https://doi.org/10. 1371/journal.pone.0238974

Hossain MA, Jahid M, Kabir I, Hossain KMA, Walton LM, Uddin Z, Haque M, Kabir M, Arafat S M (2020) Knowledge, attitudes, and fear of COVID-19 during the Rapid Rise Period in Bangladesh. PLoS ONE 15(9):1-13

Islam R (2020) COVID-19 Resilient Village in Bangladesh. ReliefWeb, UNICEF, Bangladesh. https://startnetwork.org/news-and-blogs/ covid-19-resilient-village-bangladesh

Islam MA, Barna SD, Raihan H, Khan MNA, Hossain MT (2020) Depression and anxiety among university students during the COVID-19 pandemic in Bangladesh: a web-based cross-sectional survey. PLoS ONE 15(8):e0238162

Islam SMD-U, Bodrud-Doza M, Khan RM, Haque MA, Mamun MA (2020) Exploring COVID-19 stress and its factors in Bangladesh: a perception-based study. Heliyon 6(7):e04399

Islam MM, Islam MS (2021) Energy consumption-economic growth nexus within the purview of exogenous and endogenous dynamics: evidence from Bangladesh. OPEC Energy Rev 44(05):opec.12195. https://doi.org/10.1111/opec.12195

Islam MS, Sarkar T, Khan SH, Kamal A-HM, Hasan SMM, Kabir A, Yeasmin D, Islam MA, Chowdhury KIA, Anwar KS (2020) COVID-19-related infodemic and its impact on public health: a global social media analysis. Am J Trop Med Hyg 103(4):1621-1629

Islam MS, Sujan MSH, Tasnim R, Ferdous MZ, Masud JHB, Kundu S, Mosaddek ASM, Choudhuri MSK, Kircaburun K, Griffiths MD (2020) Problematic internet use among young and adult population in Bangladesh: Correlates with lifestyle and online activities during the COVID-19 pandemic. Addict Behav Rep 12:100311

Jenatabadi HS, Ismail NA (2014) Application of structural equation modelling for estimating airline performance. J Air Transp Manag 40:25-33

Khasawneh AI, Humeidan AA, Alsulaiman JW, Bloukh S, Ramadan M, Al-Shatanawi TN, Awad HH, Hijazi WY, Al-Kammash KR, Obeidat N, Saleh T (2020) Medical students and COVID-19: Knowledge, attitudes, and precautionary measures. A descriptive study from Jordan. Front Public Health 8:253. https://doi.org/10. 3389/2Ffpubh.2020.00253

Lancet T (2020) COVID-19: fighting panic with information. Lancet 395(10224):537

Leung L (2009) User-generated content on the internet: an examination of gratifications, civic engagement and psychological empowerment. New Media Soc 11(8):1327-1347

Li C, Chen LJ, Chen X, Zhang M, Pang CP, Chen H (2020) Retrospective analysis of the possibility of predicting the COVID-19 outbreak from Internet searches and social media data, China, 2020. Eurosurveillance 25(10):2000199

Lin C-Y, Broström A, Griffiths MD, Pakpour AH (2020) Investigating mediated effects of fear of COVID-19 and COVID-19 misunderstanding in the association between problematic social media use, psychological distress, and insomnia. Internet Interv 21:100345

Livingstone S, Bober M, Helsper EJ (2005) Active participation or just more information? Young people's take-up of opportunities to act and interact on the Internet. Inf, Commun Soc 8(3):287-314

Lohiniva A-L, Sane J, Sibenberg K, Puumalainen T, Salminen M (2020) Understanding coronavirus disease (COVID-19) risk perceptions among the public to enhance risk communication efforts: a practical approach for outbreaks, Finland, February 2020. Eurosurveillance 25(13):2000317 
Mian A, Khan S (2020) Coronavirus: the spread of misinformation. BMC Med 18(1):1-2

Mohiuddin AK (2019) Diabetes fact: Bangladesh perspective. Int J Diab Res 2(1):14-20

Mueller RO, Hancock GR (2001) Factor analysis and latent structure: confirmatory factor analysis. In: Smelser NJ, Baltes PB (eds) International encyclopedia of the social and behavioral sciences. Pergamon, Oxford, pp 5239-5244

Naeem S. Bin, Bhatti R, Khan A (2020) An exploration of how fake news is taking over social media and putting public health at risk. Health Inf Lib J. https://doi.org/10.1111/hir.12320

Ng FK, Wallace S, Coe B, Owen A, Lynch J, Bonvento B, Firn M, McGrath BA (2020) From smartphone to bed-side: exploring the use of social media to disseminate recommendations from the National Tracheostomy Safety Project to front-line clinical staff. Anaesthesia 75(2):227-233

Ni MY, Yang L, Leung CMC, Li N, Yao XI, Wang Y, Leung GM, Cowling BJ, Liao Q (2020) Mental health, risk factors, and social media use during the COVID-19 epidemic and cordon sanitaire among the community and health professionals in Wuhan, China: cross-sectional survey. JMIR Mental Health 7(5):e19009

Radwan E, Radwan A (2020a) The spread of the pandemic of social media panic during the COVID-19 outbreak. Euro J Environ Public Health 4(2):em0044

Radwan E, Radwan A, Radwan W (2020b) The role of social media in spreading panic among primary and secondary school students during the COVID-19 pandemic: an online questionnaire study from the Gaza Strip. Palestine Heliyon 6(12):e05807

Robinson RS (2014) Purposive sampling. Encycl Qual Life Well-Being Res 6:5243-5245

Ruggiero TE (2000) Uses and gratifications theory in the 21st century. Mass Commun Soc 3(1):3-37

Rzymski P, Nowicki M (2020) Preventing COVID-19 prejudice in academia. Science 367(6484):1313

Sahni H, Sharma H (2020) Role of social media during the COVID-19 pandemic: beneficial, destructive, or reconstructive? Int J Acad Med 6(2):70

Sampa MB, Hoque M, Islam R, Nishikitani M, Nakashima N, Yokota F, Kikuchi K, Rahman MM, Shah F, Ahmed A (2020) Redesigning portable health clinic platform as a remote healthcare system to tackle COVID-19 pandemic situation in unreached communities. Int J Environ Res Public Health 17(13):4709

Schutt RK (2018) Investigating the social world: the process and practice of research. Sage publications, London

Shah V, Lance R, Holbert D, Dhavan NK (2001) "Connecting" and" disconnecting" with civic life: patterns of Internet use and the production of social capital. Polit Commun 18(2):141-162

Shimizu K (2020) 2019-nCoV, fake news, and racism. Lancet 395(10225):685-686

Simon Kemp (2020) Digital 2020: Bangladesh. DATAREPORTAL. https://datareportal.com/reports/digital-2020-bangaldesh

Soltaninejad K (2020) Methanol mass poisoning outbreak, a consequence of COVID-19 pandemic and misleading messages on social media. Int J Occup Environ Med 11(3):148
Srivastava KC, Shrivastava D, Chhabra KG, Naqvi W, Sahu A (2020) Facade of media and social media during Covid-19-a review. Int J Res Pharm Sci. https://doi.org/10.26452/ijrps.v11iSPL1.2288

Swazo NK, Talukder MMH, Ahsan MK (2020) A duty to treat? A right to refrain? Bangladeshi physicians in moral dilemma during COVID-19. Philos Ethics Humanit Med 15(1):1-23

Tasnim S, Hossain MM, Mazumder H (2020) Impact of rumors and misinformation on COVID-19 in social media. J Prev Med Public Health 53(3):171-174

Wang D, Hu B, Hu C, Zhu F, Liu X, Zhang J, Wang B, Xiang H, Cheng Z, Xiong Y (2020) Clinical characteristics of 138 hospitalized patients with 2019 novel coronavirus-infected pneumonia in Wuhan, China. JAMA 323(11):1061-1069

Wang C, Pan R, Wan X, Tan Y, Xu L, Ho CS, Ho RC (2020) Immediate psychological responses and associated factors during the initial stage of the 2019 coronavirus disease (COVID-19) epidemic among the general population in China. Int J Environ Res Public Health 17(5): 1729

Whiting A, Williams D (2013) Why people use social media: a uses and gratifications approach. Int J Qual Market Res. https://doi.org/ 10.1108/QMR-06-2013-0041

Williamson K (2002) Research methods for students, academics and professionals: information management and systems. Elsevier, Wagga Wagga

Wong JEL, Leo YS, Tan CC (2020) COVID-19 in Singapore-current experience: critical global issues that require attention and action. JAMA 323(13): 1243-1244

World Health organization (WHO). (2021). Coronavirus disease (COVID-19) update. World Health Organization (WHO). https://www.who.int/bangladesh/emergencies/coronavirus-disea se-(covid-19)-update/

Worldometer. (2020). COVID-19 Coronavirus Pandemic. Worldometer. https://www.worldometers.info/coronavirus/

Yadav M, Joshi Y, Rahman Z (2015) Mobile social media: The new hybrid element of digital marketing communications. Procedia Soc Behav Sci 189(1):335-343

Yanti B, Wahyudi E, Wahiduddin W, Novika RGH, Arina YMD, Martani NS, Nawan N (2020) Community knowledge, attitudes, and behavior towards social distancing policy as prevention transmission of COVID-19 in indonesia. J Admin Kesehatan Indonesia $8(2): 4-14$

Zhao Y, Zhang J (2017) Consumer health information seeking in social media: a literature review. Health Info Libr J 34(4):268-283

Publisher's Note Springer Nature remains neutral with regard to jurisdictional claims in published maps and institutional affiliations. 